\section{Microscopy Coming Events}

2015

19th Conference on Microscopy of

Semiconducting Materials

March 29-April 2, 2015

Cambridge, UK

http://msm2015.iopconfs.org/home

2015 MRS Spring Meeting \& Exhibition April 6-10, 2015

San Francisco, CA

www.mrs.org/spring2015

Biology of Regenerative Medicines April 22-24, 2015

Cambridge, UK

https://registration.hinxton.wellcome.ac.uk/

display_info.asp?id=432

EMAS 2015: Workshop on Microbeam

Analysis

May 3-7, 2015

Portoroz, Slovenia

www.microbeamanalysis.eu/events

15th Meeting of the European Light

Microscopy Initiative (ELMI)

May 19-23, 2015

Barcelona, Spain

www.elmi2015.eu

Inter/Micro 2015

June 8-12, 2015

Chicago, IL

www.mcri.org

Microscience Microscopy Conference June 29-July 2, 2015

Manchester, United Kingdom

www.mmc2015.org.uk

Microscopy \& Microanalysis 2015

August 2-6, 2015

Portland, OR

www.microscopy.org

\section{6}

Microscopy \& Microanalysis 2016

July 24-28, 2016

Columbus, $\mathrm{OH}$

www.microscopy.org

2017

Microscopy \& Microanalysis 2017

July 23-27, 2017

St. Louis, MO

www.microscopy.org

2018

Microscopy \& Microanalysis 2018

August 5-9, 2018

Baltimore, MD

www.microscopy.org

2019

Microscopy \& Microanalysis 2019

August 4-8, 2019

Portland, OR

www.microscopy.org

More Meetings and Courses

Check the complete calendar near the back of this magazine.

\title{
Microscopy Reveals That It's Written in Stone!
}

\author{
Stephen W. Carmichael \\ Mayo Clinic, Rochester, MN 55905 \\ carmichael.stephen@mayo.edu
}

The study of ancient art provides information as to when cognition first appeared in human evolution. Because of its durability, this is usually restricted to carvings on stone or other durable surfaces in habitable caves. One such cave was formed by intense wave action and is located on the Mediterranean coast of Gibraltar, a small promontory situated at the southern extreme of the Iberian Peninsula. Recently a large international group including Joaquin RodriguezVidal, Francesco d'Errico, and Clive Finlayson determined that engravings in the stone of this cave were made by Neanderthals [1].

An engraving was found on a flat area of about $300 \mathrm{~cm}^{2}$. It consisted of eight deeply engraved lines forming an incomplete criss-cross pattern, obliquely intersected by short thin lines. The engraved pattern was strikingly different from natural fissures that were also found on exposed surfaces in the cave.

Using light optical microscopy and scanning electron microscopy, RodriguezVidal et al. were able to determine that a series of grooves were made with unique movements of a stone tool tip (Figure 1). Experimenting with a series of likely stone tools, they estimated that the engraving would require about 200 deliberate blows of a hammer-like device on the stone tool. Specifically, some of the lines were engraved with a robust stone point by repeatedly passing the tool tip into the groove in the same direction. Remarkably it was apparent that no accidental marks were made outside the pattern, and there was only one place where the end of a line was fringed. This suggests that a reasonably skilled person, or group of people, made the engraving. Other experiments ruled out that the marks were made for a

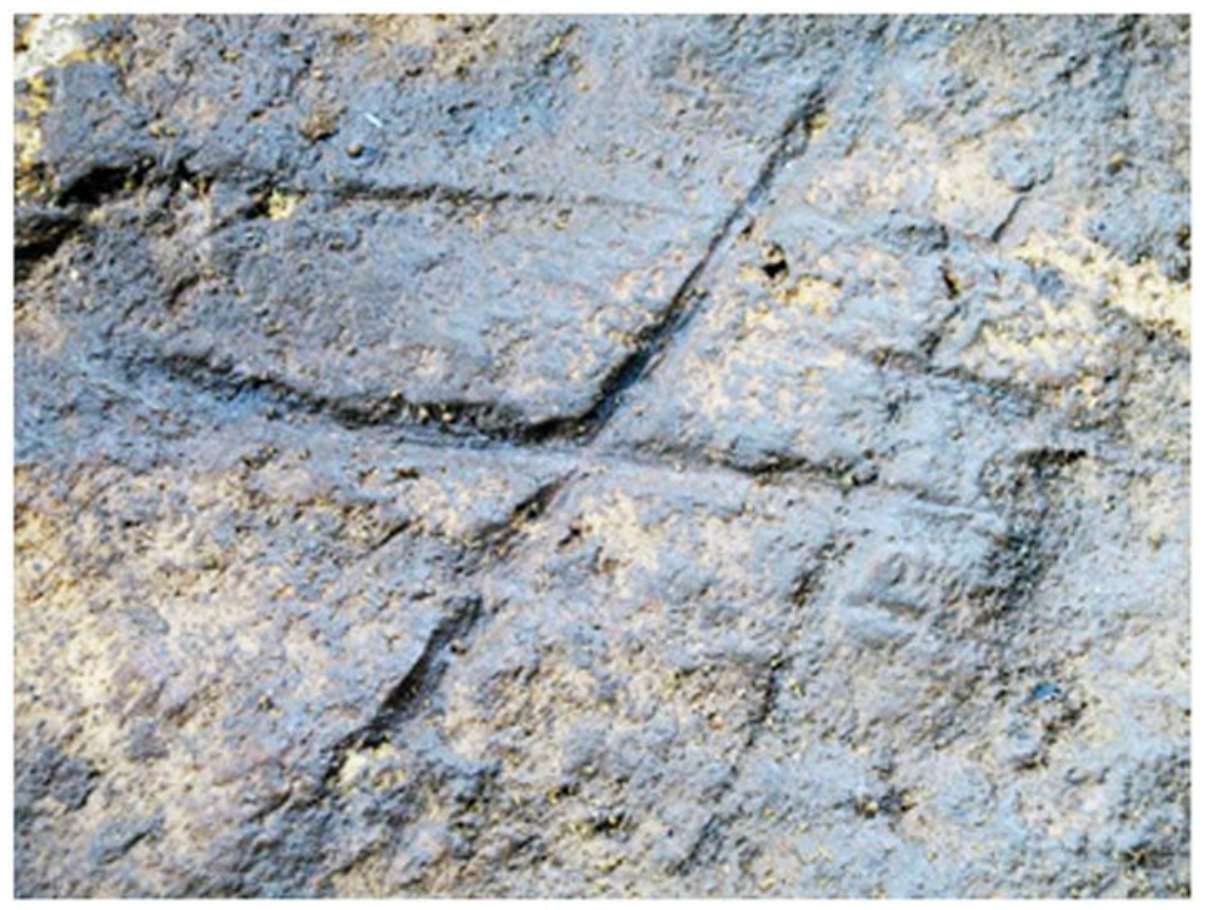

Figure 1: Engraving made by Neanderthals in a Gibraltar cave required an estimated 200 strokes of a stone tool. 
utilitarian purpose, such as a stone where animal skins were processed.

Rodriguez-Vidal et al. estimated that the engraving was made about 39,000 years ago. This is the earliest time that this was done (terminus ante quem in anthropologic terminology), and at that time it is known that Neanderthals inhabited Iberian Peninsula and modern humans did not. The significance of this to the field of anthropology is enormous! The production of purposely made engraved or painted designs on cave walls is recognized as a major cognitive step in human evolution. This had been considered to be restricted to modern humans. The engraving in this cave represents the first directly demonstrable case in which a technically elaborated, consistently and carefully made non-utilitarian engraved abstract pattern, whose production required prolonged and focused actions, has been observed on the bedrock of a cave. For the first time, Rodriguez-Vidal et al. demonstrated the capacity of Neanderthals for abstract thought and expression.

\section{References}

[1] J Rodriguez-Vidal et al., Proc Nat Acad Sci 111 (2014) 13301-06.

[2] The author gratefully acknowledges Professor Clive Finlayson for reviewing this article.

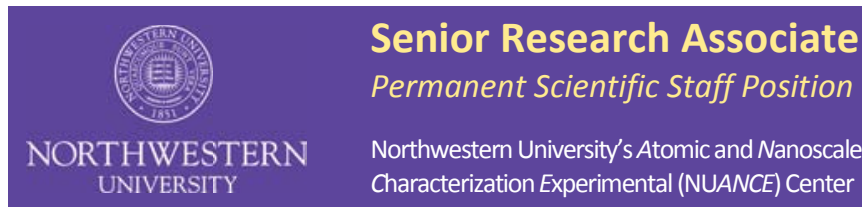

The NUANCE Center invites you to apply for a Senior Research Associate to oversee research, collaboration and training related to the Scanning Transmission and Transmission Electron Microscopy (S/TEM) facilities.

The preferred candidate will have obtained a $\mathrm{PhD}$ in Materials Science, Physics or related physical science/engineering field. The preferred candidate will have at least 3 years of experience in advanced S/TEM analysis, related analytical techniques and sample preparation methods for physical science/engineering materials. Proven publication record utilizing advanced S/TEM techniques and applications is essential.

The selected candidate will be responsible for training and assisting users on conventional and advanced S/TEM, including aberration-corrected S/TEM, facilitating laboratory sessions for microscopy courses, and conducting analysis and characterization using electron microscopes. There are ample opportunities for independent and collaborative research utilizing advanced S/TEMs. The selected candidate will regularly operate conventional and advanced S/TEM analysis, consult and collaborate with users on experiment design \& research in electron microscopy, sample preparation and general lab equipment.

Applications should include: 1. Introduction letter; 2. Curriculum Vitae 3. Statement of plans for research; 4 . Contact information for three references

For more information and to apply, visit: http://bit.ly/SeniorRA

Northwestern University is an Equal Opportunity, Affirmative Action Employer of all protected classes including veterans and individuals with disabilities.

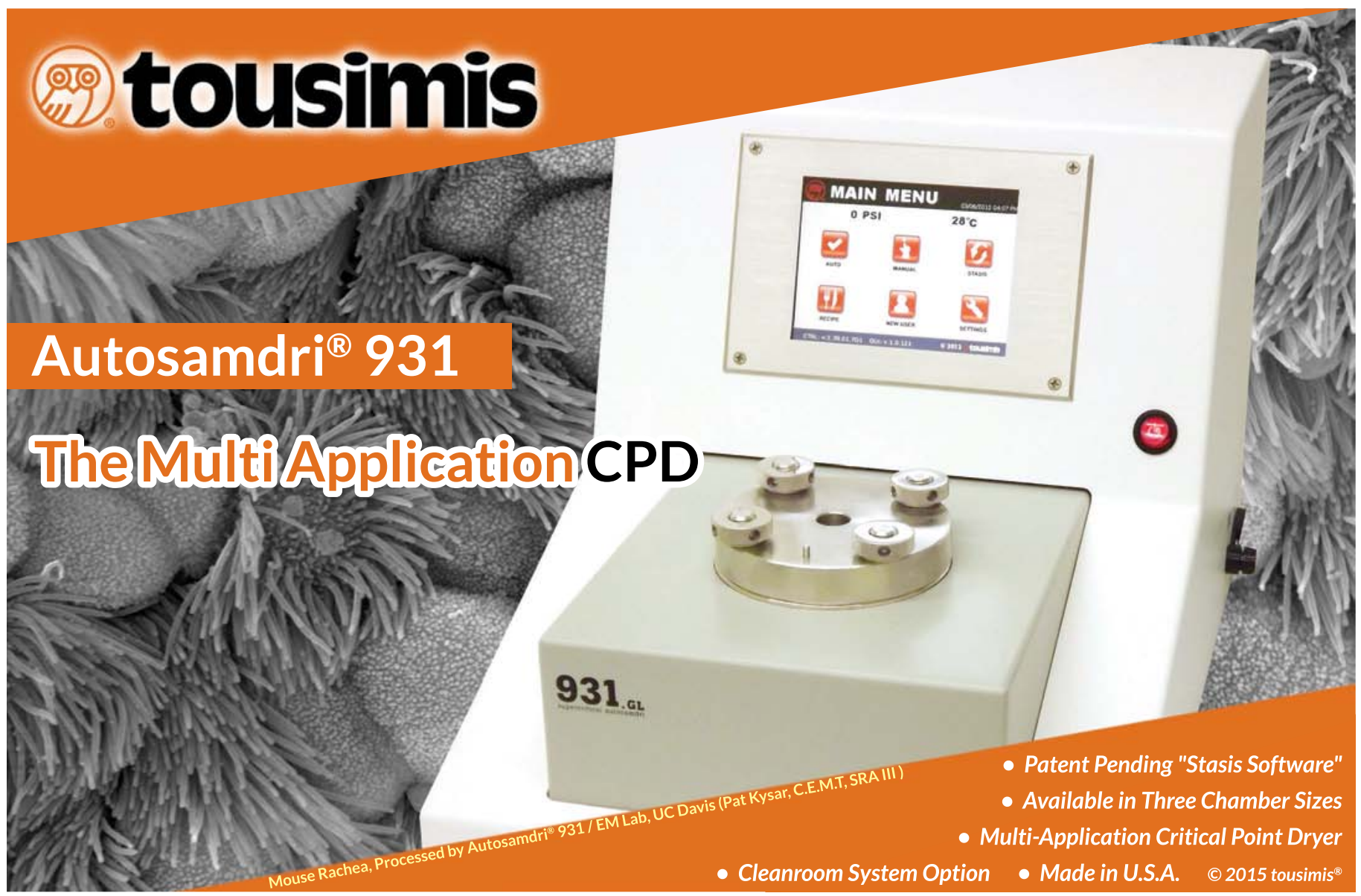




\section{A Leap in Sensitivity
and Speed with the \\ A Leap in Sensitivity
and Speed with the \\ XR401 sCMOS \\ Camera}

Cryo TEM

- Low Dose TEM

- Diffraction

- In-Situ TEM

- Extraordinary speed

- Non-Blooming Sensor - $<2$ e/pixel noise

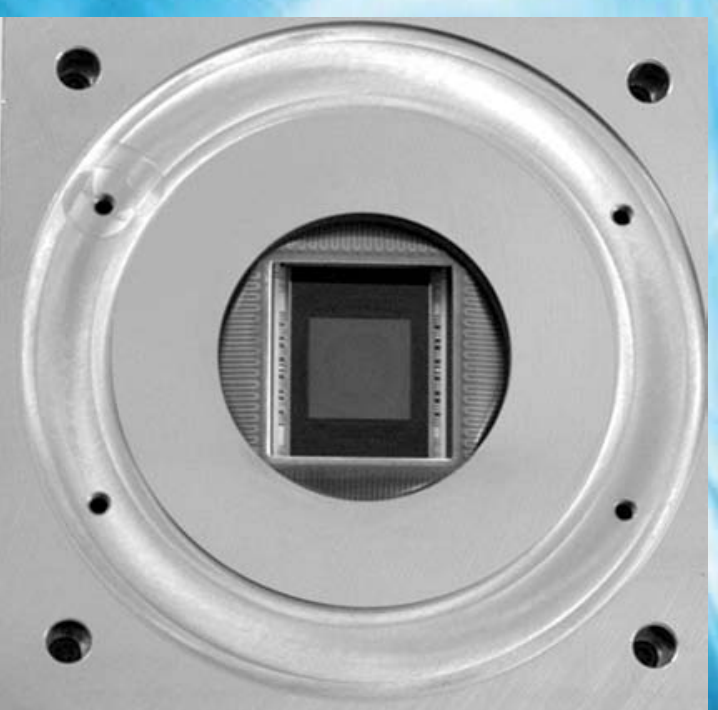

Adenovirus

Dr. Cameron Ackerley

The Hospital for Sick Children
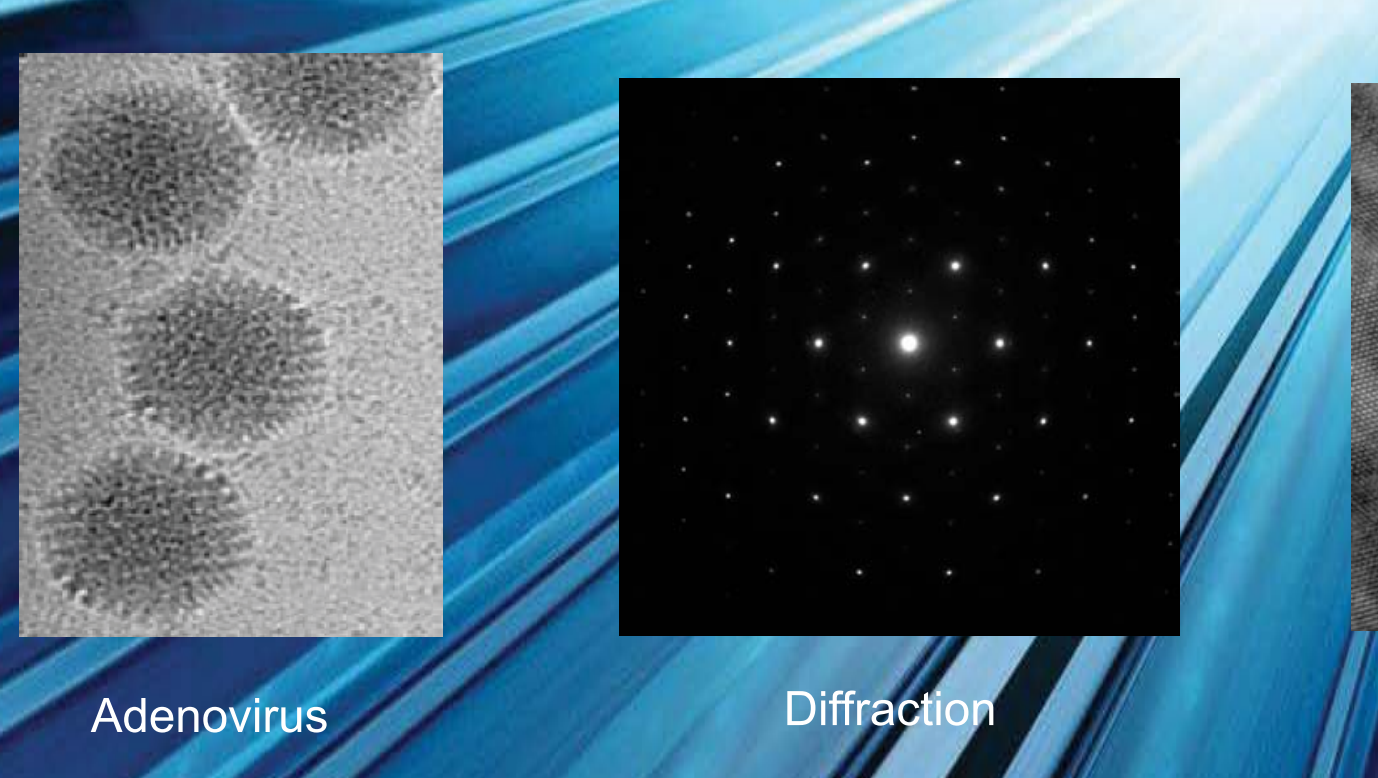

Lattice 